\title{
FIRST EXPERIENCE WITH THE USE OF ICF CLASSIFICATION TO EVALUATE PATIENTS WITH PROGRESSIVE NEUROLOGICAL DISEASE IN RESEARCH
}

\author{
Jarmila Siverová, Radka Bužgová, Radka Kozáková \\ Faculty of Medicine, University of Ostrava, Ostrava, Czech Republic
}

\begin{abstract}
Neurological conditions are associated with a high level of disability, which affects the overall quality of life of patients and their integration in society. As the disease progresses, self-sufficiency and mobility gradually deteriorate. These limitations are made easier by the use of appropriate compensatory aids and the modification of the environment. The sample included a total of 56 patients with neurological diseases-Multiple Sclerosis (41), Parkinson's disease (14), and Amyotrophic Lateral Sclerosis (1). Women prevailed in the sample, accounting for $73 \%$. The average age of the patients in the sample was 59.4, ranging from 38 to 81 years. Clinical forms of the ICF classification (International Classification of Functioning, Disability and Health) were used to record the information on the functional state of the patients. The most information was obtained from the ICF classification component Restrictions on Activities and Participation. The qualifiers of performance and capacity point out the supportive use of assistance (e.g. adjustment of the environment, compensatory aids) to improve the participation in patient's life. Through a comprehensive evaluation of the patient's functional health using the ICF classification, we can obtain his/her functional profile. This information can be used when planning the nursing and rehabilitation care.
\end{abstract}

\section{Keywords}

International Classification of Functioning, Disability and Health, neurological disease, rehabilitation care, functional state, care planning

\section{Introduction}

Patients with progressive neurological disease are characterized by a high degree of disability, which significantly affects their quality of life, including their integration in the society. As the disease progresses, we can see increasing symptoms of reduced ability of selfcare and varying degrees of mobility impairment in these patients [1]. The deterioration of self-sufficiency and reduced mobility can be made easier by using appropriate compensatory aids and adjusting the environment [2].

The International Classification of Functioning, Disability and Health (ICF) of the World Health Organization offers a tool for the communication of professionals using codes that describe the functional state of patients in different healthcare facilities and in different health conditions [3]. The ICF classification can be used for statistical purposes (for data collection and recording), for research (for measuring the quality- of-life outcomes or the environmental factors), in clinical practice (for the needs of assessment or evaluation of medical treatments), for social and health policy (planning of social security or health and social policy). In research, it allows for surveying and comparing data from various regions and countries. The ICF was introduced in the Czech Republic on 1st October 2020 by the Czech Statistical Office in cooperation with the Ministry of Health by CZSO (Czech Statistical Office) Communication No. 377/2020 Coll. (part 152) [4].

Within the ICF classification, specific questionnaires containing specific sets-the so-called "ICF core sets"-were created. These questionnaires contain basic terms that are crucial to assessing the functional state of a patient with a specific type of disease. The individual "core sets" are available either as complex forms with larger amount of terms from different chapters or in a short version, which is less comprehensive [4].

There is an international electronic portal that contains selected "core sets", which can be supplemented with more ICF codes, and then it is possible to 
fill out, save, or print the created form. A similar browser with the electronic version of the "core sets" in the Czech language, which is being prepared by the Institute of Health Information and Statistics of the Czech Republic (IHIS CR), should also be created in the Czech Republic [4]. Currently, ICF specific checklists are created according to the ICF WHO core sets in the MS Word format in the Czech version. By using these checklists, it is possible to find out which codes appear most often in a specific group of patients and should be primarily included in the electronic checklists. Certain pre-selection of the codes can make it easier and faster for doctors to fill out the form.

The aim of this study was to describe the first experience with the use of the Czech version of selected core sets for the evaluation of patients according to the International Classification of Functioning, Disability and Health in research of patients with selected neurological diseases. Based on the patient evaluations. The aim was also to recommend the frequently occurring codes that should be considered when creating the electronic version of the form.

\section{Methods}

The sample included patients who participated in an intervention study under the project of the AZV MZ CR no. 17-29447A: "Neuropalliative and rehabilitation approach to maintain the quality of life of patients in advanced stage of selected neurological diseases". The selection criteria for inclusion of patients in the research sample were as follows: patient with selected PND (Multiple Sclerosis, Parkinson's disease, Atypical Parkinsonism, Amyotrophic Lateral Sclerosis); age $18+$ years; PPS (Palliative Performance Scale) $\leq 70$ points; consent to cooperation. The patients were contacted and enrolled in the study at a selected rehabilitation institution. A total of 56 patients were included, with a predominance of women who represented $73 \%$ of the sample. The average age of the patients in the sample was 59.4, ranging from 38 to 81 years.

There were 41 patients with Multiple Sclerosis (MS). The severity of the patients' disability was expressed using a disability quantifying score (EDSS score) of 7.3. This value represents difficult to impossible mobility, dependence on care, passive transport, only basic self-sufficiency. There were 14 patients with Parkinson's disease (PD) in the stage according to Hoehn and Yahr (rating scale) of 3 and 4. This stage means the presence of muscle tension, frequent falls, and dependence on help. There was 1 patient with Amyotrophic Lateral Sclerosis (ALS) in the sample with the severity of the disease, according to the scale of functional assessment of the revised functional scale (ALSFRS_R), reaching the score of 20. This scale depicts the disease progression on a scale of 48 (no stiffness) -0 (complete stiffness).

The Czech versions of the checklists of the ICF IHIS CR 2018 classification were used to record the data about the patients. For patients with MS, the clinical form of the Core Set Multiple Sclerosis (45) was used. For patients with PD and ALS, the clinical form of the Core Set Geriatrics (65) was used.

Clinical forms are checklists of selected categories of the ICF classification. They are used to obtain and record information about the functioning and disability of the patients. The forms are divided into three parts: Disorders of body functions, Disorders of body structures, Restrictions on activities and participation. In each section, the components are quantified on the same general scale $0-4$, which determines the degree of the problem, where 0 means no disorder, $1-$ mild disorder, 2 - moderate disorder, 3 - severe disorder and 4 - complete disorder. Further, 8 means that the disorder cannot be specified, and 9 means that the code is not applicable.

Part 1 a) Disorders of body functions, includes the qualifier of the extent of the disorder which expresses the problem in body functions such as a significant deviation or loss. Part $1 \mathrm{~b}$ ) Disorders of body structures, contains qualifiers of the extent of the disorder, the nature of the change, and the location. The qualifiers express the problems of the structures, such as a significant deviation or loss. The second part, Restrictions on activities and participation, contains a performance qualifier (performing an activity, describes the extent of the patient's restricted participation when performing the activity in his/her natural environment) and a capacity qualifier (describes the extent of the patient's limited activity when performing tasks or activities without assistance, participation in a life situation). The third part, Environmental factors, contains the facilitation and barrier qualifiers.

The checklists were completed based on the documentation obtained from selected patients under the above-mentioned research project. These were documents from the medical facility (reports on the initial examination by the doctor, final report of the doctor, reports of the physiotherapist, occupational therapist, and psychologist) and evaluation scales evaluated by the doctor and the research coordinator when including the patients in the research sample. The following evaluation scales were used for the assessment: a scale for the quantification of the disabilities of patients with multiple sclerosis (Expanded Disability Status Scale EDSS), a scale for the evaluation of the functional state of patients with amyotrophic lateral sclerosis (Revised Amyotrophic Lateral Sclerosis Functional Rating Scale - ALS FRS_R), a scale for the evaluation of activities of daily living (Activities of Daily Living - ADL), a scale of palliative functional competence (Palliative Performance Scale - PPS), universal nutrition screening, evaluation of disease progression, quality of life evaluation (Progressive neurological quality of life 
questionnaire - PNDQoL), needs scale (NPCS - Needs Provision and Complexity Scale for Long Term Neurological Conditions).

\section{Results}

Evaluation of the clinical form of the Core Set Geriatrics (65)

The highest frequency of codes was found in the section Restrictions on activities and participation. More than $90 \%$ detection of responses was found with respect to 24 codes in this section. Changing basic body position (performance qualifier), Using communication devices and techniques (performance qualifier), Transferring (performance and capacity qualifier), Walking (performance and capacity qualifier), Moving around in different locations (performance and capacity qualifier), Moving around using equipment (performance and capacity qualifier), Washing oneself (performance and capacity qualifier), Caring for body parts (performance and capacity qualifier), Toileting (performance and capacity qualifier), Eating (performance and capacity qualifier), Family relationships (performance and capacity qualifier), Basic economic transacttions (performance and capacity qualifier). For these codes, the effect of assistance on reducing the extent of the disorder was identified. The number of selected (most frequent) codes are depicted in Table 1 and in Fig. 1.

Table 1: Number of selected codes of the form Geriatrics (65).

\begin{tabular}{|c|c|c|c|c|c|}
\hline \multirow{2}{*}{$\begin{array}{l}\text { Part } 2 \text { Restrictions on } \\
\text { activities and } \\
\text { participation } \\
\text { Codes }\end{array}$} & \multicolumn{5}{|c|}{$\begin{array}{l}\text { Extent of disorder - } \\
\text { performance qualifier }\end{array}$} \\
\hline & 0 & 1 & 2 & 3 & 4 \\
\hline $\begin{array}{l}\text { Changing basic body } \\
\text { position }\end{array}$ & 11 & 8 & 3 & 3 & 5 \\
\hline $\begin{array}{l}\text { Using communication } \\
\text { devices and } \\
\text { techniques }\end{array}$ & 3 & 1 & 1 & 0 & 4 \\
\hline Transferring & 9 & 8 & 3 & 7 & 4 \\
\hline Walking & 3 & 3 & 7 & 7 & 5 \\
\hline $\begin{array}{l}\text { Moving around in } \\
\text { different locations }\end{array}$ & 3 & 4 & 6 & 4 & 11 \\
\hline $\begin{array}{l}\text { Moving around using } \\
\text { equipment }\end{array}$ & 12 & 1 & 5 & 2 & 6 \\
\hline Washing oneself & 2 & 3 & 11 & 9 & 7 \\
\hline Caring for body parts & 2 & 3 & 11 & 9 & 7 \\
\hline Toileting & 6 & 2 & 3 & 4 & 6 \\
\hline Eating & 5 & 3 & 11 & 8 & 4 \\
\hline Family relationships & 16 & 1 & 2 & 0 & 0 \\
\hline $\begin{array}{c}\text { Basic economic } \\
\text { transactions }\end{array}$ & 12 & 1 & 1 & 0 & 4 \\
\hline
\end{tabular}

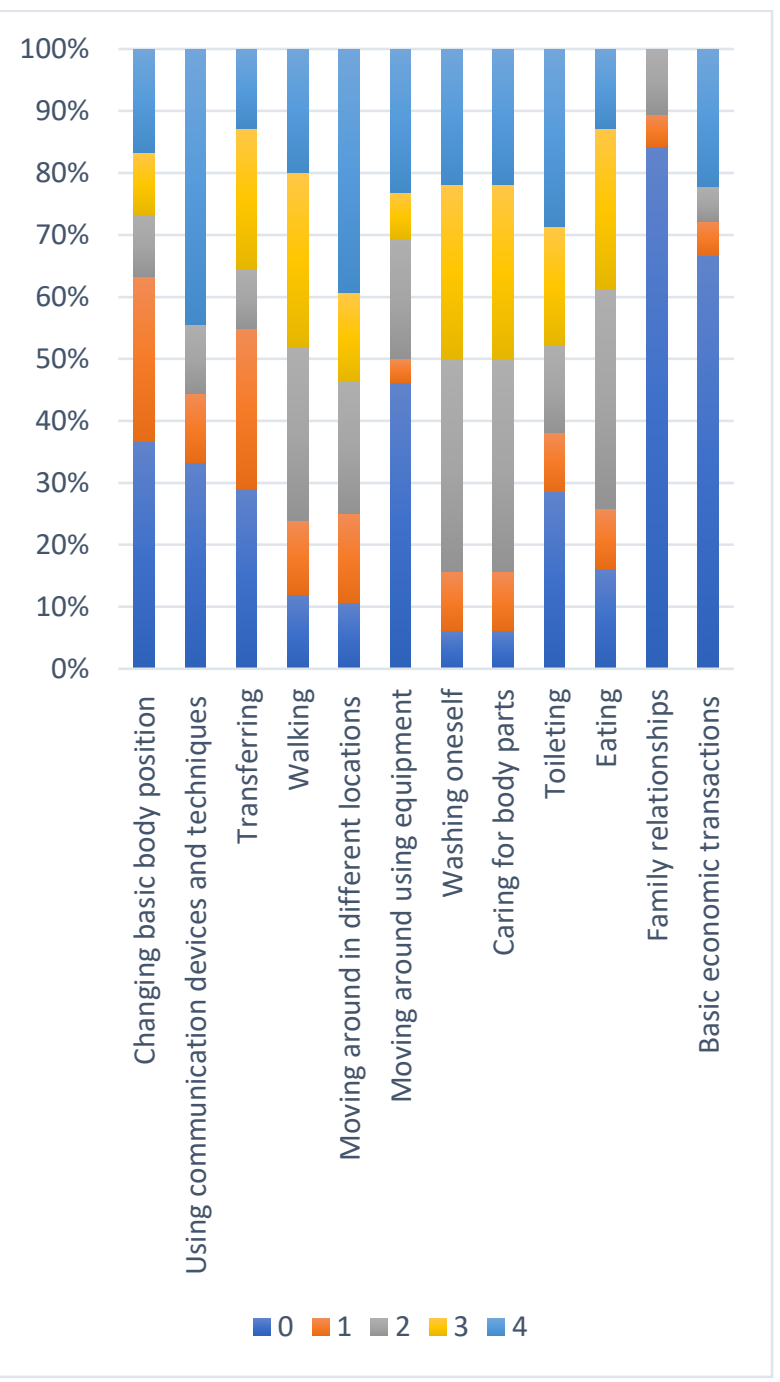

Fig. 1: Ratio of selected codes of the form Geriatrics (65).

In the section of the Disorders of body functions, 4 codes were detected regarding the qualifier of the disorder extent: Sleep functions, Immunological system functions, Functions of the cardiovascular and respiratory sensations, Urinary functions. No codes were detected in the section of the Disorders of body structure, and 3 codes were identified in the Environmental factors section: Products or substances for personal consumption (food, medicine), Health professionals, Social security services, systems, and policies.

\section{Evaluation of the clinical form of the Core Set Multiple Sclerosis (45)}

The highest frequency of codes was found in the section Restrictions on activities and participation. More than $90 \%$ detection of responses was found with respect to 10 codes in this section: Solving problems (performance and capacity qualifier), Undertaking multiple tasks (performance and capacity qualifier), Walking (performance and capacity qualifier), Family 
relationships (performance and capacity qualifier), Remunerative employment (performance and capacity qualifier). The effect of assistance on reducing the extent of the disorder was identified for these codes. Their overview including the extent of the disorder regarding the performance qualifier is provided in Table 2 and in Fig. 2.

In the Disorders of body functions section, more than 90\% was recorded for 6 codes: Energy and drive functions, Emotional functions, Higher-level cognitive functions, Urinary functions, Muscle power functions, Gait pattern functions. No code was detected in the Disorders of body structure and Environmental factors sections.

Table 2: Number of selected codes of the form Multiple sclerosis (45).

\begin{tabular}{lccccc}
\hline $\begin{array}{l}\text { Part } 2 \text { Restrictions } \\
\text { on activities and } \\
\text { participation }\end{array}$ & \multicolumn{5}{c}{ Extent of disorder - } \\
performance qualifier \\
Codes & $\mathbf{0}$ & $\mathbf{1}$ & $\mathbf{2}$ & $\mathbf{3}$ & $\mathbf{4}$ \\
\hline $\begin{array}{l}\text { Solving problems } \\
\text { Undertaking }\end{array}$ & 10 & 25 & 26 & 13 & 2 \\
$\quad$ multiple tasks & 5 & 9 & 17 & 23 & 20 \\
$\begin{array}{l}\text { Walking } \\
\text { Family }\end{array}$ & 4 & 6 & 11 & 28 & 32 \\
$\quad \begin{array}{l}\text { relationships } \\
\text { Remunerative }\end{array}$ & 8 & 16 & 44 & 10 & 0 \\
$\quad$ employment & 0 & 0 & 0 & 0 & 82 \\
\hline
\end{tabular}

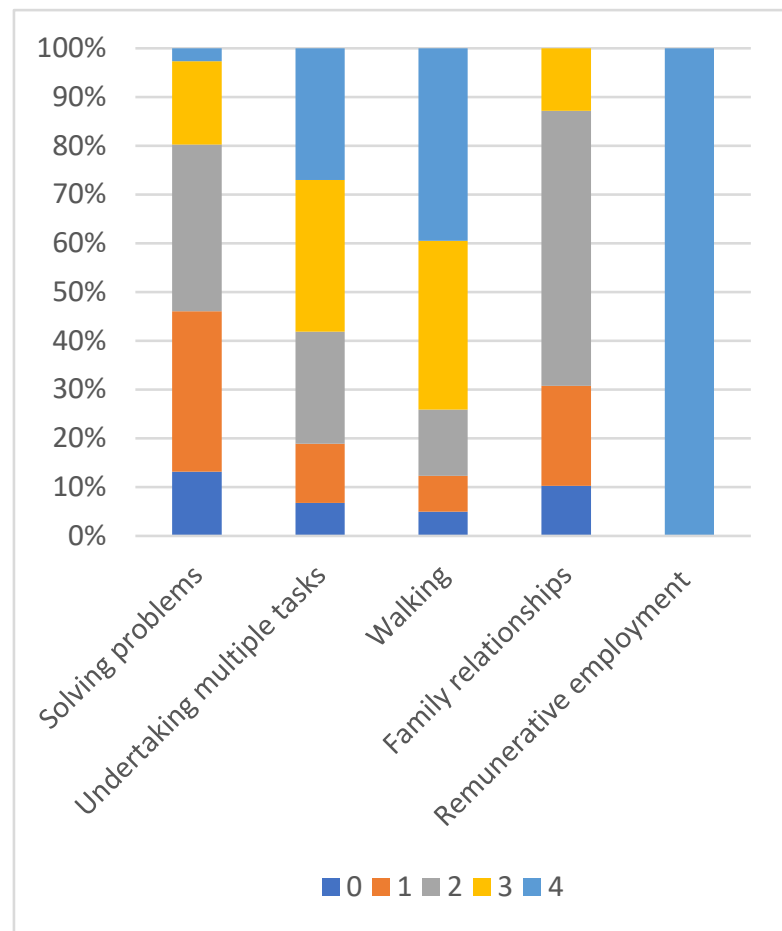

Fig. 2: Ratio of selected codes of the form Multiple sclerosis (45).

\section{Discussion}

In our research, we found out that the use of Geriatrics and Multiple Sclerosis core sets in clinical practice is appropriate for patients with progressive neurological disease. The highest frequency of codes was detected for both core sets in the section Restrictions on activities and participation. The electronic version of the core sets may facilitate the evaluation of patients using ICF, which is appropriate for patients with progressive neurological disease. In foreign research focused on the functional state of patients with progressive neurological and neurodegenerative diseases, the use of the ICF classification was also found to be useful. In our small sample of patients, we encountered obstacles in the project in the form of a lack of input information when working with the documentation. Some results regarding the section of Restrictions on activities and participation correspond to the conclusions of foreign research. The patients with ALS and MS face problems from all categories of the ICF classification [5]. Among the categories of ICF classification identified in the patients with ALS and MS, they found more congruities than in respondents with other neurological diagnoses. E.g. in the "body function" component it was $50 \%$ of the categories, which is in line with the disadvantageous nature of both diseases [6]. These results, as well as our findings, show that the main areas of the restriction on activities and participation are mobility, self-care, general tasks and requirements, domestic life, interpersonal interactions, and relationships. Understanding the personality factors is also necessary to provide optimal care for patients with ALS [7]. The ICF appropriately integrates the perspectives of ALS patients and caregivers, which may allow for further development of ICF categories and optimization of care and care burden [2].

Environmental factors are mostly mentioned as facilitators [8]. Environmental factors are described as products and technologies, the natural environment, support and relationships, services, systems, and policies [5]. Our findings are in line with these results - as the facilitators in environmental factors, we also identified services, systems, policies, and professional support in the group of patients with Parkinson's disease. For the patients with Parkinson's disease, the need for coordinated care in neurology, rehabilitation and palliative care and the use of the concept of functional mobility for everyday functioning is emphasized [9].

\section{Conclusion}

Through a comprehensive evaluation of the patient's functional health situation, we obtain his/her functional 
profile identifying the person's biopsychosocial needs. From the material that was used to clarify the overall situation of the patient, most often it was possible to use the codes from the section Restrictions on activities and participation. The performance and capacity qualifiers point out the supportive use of assistance such as environment adjustment, compensatory aids to improve participation in patient's life. In the part of the classification-Disorders of body structures-it was not possible to use it due to lack of input information. The part of the classification-Disorders of body functions-provided information on the areas in which the most common problems occur (e.g. emotional, cognitive functions) and these findings can also help create a functional profile of the patient. The environmental factors provided a limited amount of information, and the results suggest a supportive impact of the system, policies, services, and healthcare professsionals. To facilitate the use of core sets in practice, we recommend offering first the codes that are more frequent in neurological patients when creating the electronic form.

\section{Acknowledgement}

The study was supported by the research project of the AZV MZ CR no. 17-29447A: "Neuropalliative and rehabilitation approach to maintain the quality of life of patients in advanced stage of selected neurological diseases".

\section{References}

[1] Hussain J, Adams D, Campbell C. End-of-life care in neurodegenerative conditions: outcomes of a specialist palliative neurology service. International Journal of Palliative Nursing. 2013;19(4):162-9. DOI: 10.12968/ijpn.2013.19.4.162

[2] Soh S, McGinley JL, Watts JJ, Iansek R, Murphy AT, Menz $\mathrm{HB}$, et al. Determinants of health-related quality of life in people with Parkinson's disease: a path analysis. Quality of Life Research. 2013;22(7):1543-53.

DOI: $\underline{10.1007 / \mathrm{s} 11136-012-0289-1}$
[3] MKF. Mezinárodní klasifikace funkčních schopností, disability a zdraví. Praha: Grada Publishing a.s., 2008.

[4] Mezinárodní klasifikace funkčních schopností, disability a zdraví. Dostupné z: www.uzis.cz

[5] Ng L, Khan F. Use of the international classification of functioning, disability and health to describe patient-reported disability: A comparison of motor neurone disease, GuillainBarré syndrome and multiple sclerosis in an Australian cohort. Disability. 2012;34(4):295-303. DOI: $10.3109 / 09638288.2011 .606345$

[6] $\mathrm{Ng} \mathrm{L}$, Khan F. International classification of functioning, disability and health and motor neurone disease rehabilitation. Social Care and neurodisability. 2013;4(1):29-41. DOI: $\underline{10.1108 / 20420911311302290}$

[7] van Uem J, Marinus J, Canning C, van Lummel R, Dodel R, Liepelt-Scarfone I, et al. Health-Related Quality of Life in patients with Parkinson's disease-A systematic review based on the ICF model. Neuroscience and Biobehavioral Reviews. 2016;61:26-34. DOI: 10.1016/j.neubiorev.2015.11.014

[8] Ng L, Khan F. Identification of Personal Factors in Motor Neurone Disease: A Pilot Study. Rehabilitation Research and Practice. 2011;2011:1-7. DOI: 10.1155/2011/871237

[9] Bouça-Machado R, Maetzler W, Ferreira J. What is Functional Mobility Applied to Parkinson's Disease? Journal of Parkinson's Disease. 2018;8(1):121-130. DOI: $\underline{10.3233 / J P D-171233}$

\author{
Radka Bužgová, MCs., Ph.D. \\ Department of Nursing and Midwifery \\ Faculty of Medicine \\ University of Ostrava \\ Syllabova 19, CZ-703 00 Ostrava \\ E-mail: radka.buzgova@osu.cz \\ Phone: +420 553461604
}

